\title{
Comparison of Full Blood Count Parameters Using Capillary and Venous Samples in Patients Presenting to the Emergency Department
}

\author{
R. Ponampalam, ${ }^{1}$ Stephanie Man Chung Fook Chong, ${ }^{2}$ and Sau Chew Tan ${ }^{1}$ \\ ${ }^{1}$ Department of Emergency Medicine, Singapore General Hospital, Outram Road, Singapore 169608 \\ ${ }^{2}$ Department of Clinical Research, Singapore General Hospital, Outram Road, Singapore 169608 \\ Correspondence should be addressed to R. Ponampalam, gaerpo@sgh.com.sg
}

Received 29 May 2012; Accepted 10 July 2012

Academic Editors: A. Banerjee, C. C. Chang, and A. Pazin-Filho

Copyright ( $) 2012$ R. Ponampalam et al. This is an open access article distributed under the Creative Commons Attribution License, which permits unrestricted use, distribution, and reproduction in any medium, provided the original work is properly cited.

\begin{abstract}
Full blood count (FBC) analysis is a common investigation done in the emergency department (ED). The aim of this study was to determine the accuracy of bedside FBC analysis using capillary blood samples from a finger stab at point of care (POC) compared to a conventional venous blood sample analysis. A total of 314 consecutive patients presenting to the ED were recruited. After consenting, a sample of the patient's venous (V) blood was obtained via venepuncture and sent to the haematology laboratory for analysis as standard practice. This was followed immediately by collection of a capillary (C) blood sample from a finger stab which was analysed at site using an automated FBC analyser at POC. Agreement between the paired samples for blood parameters including the total white cell count, hemoglobin, and platelet count was assessed by the statistical method of Bland and Altman using V sample as the gold standard. The results showed a statistically significant deviation between capillary and venous samples only for platelet counts $(P<0.001)$ and haemoglobin $(P<0.001)$. However, the magnitudes of this difference $7.3 \times 109 / \mathrm{L}$ and $0.5 \mathrm{~g} / \mathrm{dL}$ respectively, were not clinically significant. The study suggest that the analysis of capillary samples for FBC parameters is a reliable and acceptable alternative to conventional methods with the benefits of being a rapid, convenient, and minimally invasive technique.
\end{abstract}

\section{Introduction}

Background. Full blood count (FBC) analysis is a common investigation done as part of the assessment of patients presenting with a variety of medical conditions to the emergency department (ED). The conventional means of doing these tests in most ED's with adult patient populations involve the collection of venous $(\mathrm{V})$ blood samples through venipuncture and storage of these in tubes for transportation to laboratory for analysis. These steps not only involve the need for technical expertise of collecting such V samples but also involve time delay before results are obtained and bedside decisions are made.

Importance. There are automated hematology analyzers that are capable of analyzing capillary (C) blood collected from a finger stab. This has reduced the difficulty of obtaining samples and allows the prompt testing of such samples at the point of care (POC) facilitating patient management.

Goals of This Investigation. The aim of this study is to determine the agreement of FBC analysis using capillary blood from a finger stab at POC compared to a conventional venous blood sample analysis at the hospital laboratory.

\section{Methods}

Study Design. A prospective, nonrandomized study design. All consecutive patients presenting to the ED and who required a FBC analysis as part of their assessment were eligible for the study. Patients who had unstable vital signs, 
TABLE 1: Precision results for FBC analyzer.

\begin{tabular}{lccc}
\hline & WBC & Plt & Hb \\
\hline CV (\%) & $4.9 \%$ & $3.5 \%$ & $1.7 \%$ \\
Specification CV (\%) & $2.0 \%$ & $3.2 \%$ & $0.8 \%$ \\
\hline
\end{tabular}

required immediate resuscitation and patients in cardiac arrest were excluded.

Setting. The ED of a tertiary care hospital for adults.

Equipment. The automated FBC analyzer (Medonic CA 620, manufacturer Boule Medical) was used to analyse capillary blood samples at POC in the ED. Evaluation of the precision of the FBC analyzer at POC compared to the haematology laboratory was done using 12 replicate analyses on normal samples provided by the analyzer's representatives. A measure of precision, coefficient of variation $(\mathrm{CV})$ was calculated for WBC, Plt, and $\mathrm{Hb}$ as shown in Table 1.

Selection of Participants. Informed consent was obtained from the patient or their relatives if the patient was incapable of giving consent before enrolment into the study. Management of the study subjects proceeded as determined appropriate by the attending physician. The study was approved by the IRB/Ethics Committee of the hospital.

Interventions. All consenting patients had both $\mathrm{V}$ and C samples taken with the latter done immediately after collection of the $\mathrm{V}$ sample. The attending physician using a syringe and needle (23 gauge) drew blood (V) sample from the antecubital vein before storage in standard EDTA tubes provided by the hospital laboratory. Manual inversions of the tubes were carried out in order to have thorough mixing to prevent clotting. The tubes were labelled with the patient's specific identifiers before dispatch to the hospital laboratory for analysis. For the collection of $\mathrm{C}$ samples, the patient had a finger stab of $1.8 \mathrm{~mm}$ depth (using medlance lancet, manufacturer High Tech Lab, HTL) performed by the attending physician. The $\mathrm{C}$ samples were collected in capillary tubes after discarding the first drop, with a sample volume of 20 microliters of blood.

Methods of Measurement. The C samples collected were analyzed immediately by the automated FBC analyzer (Medonic CA 620, manufacturer Boule Medical) at the POC in the ED. The attending physician who collected the specimen introduced the capillary tube containing the $\mathrm{C}$ blood sample via the cassette provided by the analyzer. Following this the analyzer would then produce a script of the FBC parameters which can also be viewed on the monitor. The data script is then labelled with the patient's details and set aside for compilation by data entry staff. The appropriately labelled $\mathrm{V}$ sample containing 3 millilitres of blood in standard FBC tube was simultaneously dispatched to the hospital laboratory for analysis by ED nursing staff through a pneumatic tube transporter system as in daily practice. The hospital laboratory (accredited by College of American Pathologists) performed analysis of FBC specimens. The results are automatically uploaded into the hospital electronic medical record databases for viewing by the physicians as soon as the samples had been analyzed. A hard copy of these results was printed for data entry staff to compile and enter into the research database. There were no rejected specimens from the laboratory for inadequate sample volume, presence of clots, or hemolysis amongst the study samples. All capillary samples were also analyzed with no rejection and hence no need for repeat sample collection and testing.

Data Collection and Processing. The blood parameters white blood cell (WBC) count, platelet count, and hemoglobin concentration from the hospital laboratory analysis of $\mathrm{V}$ sample were obtained from computerized hospital laboratory records. The results from $\mathrm{C}$ samples analyzed by Medonic CA 620 were collated for all patients at POC. All data were compiled by research assistants, matched on patient-specific details, and entered as paired data $(\mathrm{V}$ and its corresponding $\mathrm{C}$ parameters) into a database in SPSS by data entry staff. This was verified by the supervisor who carried out random checks on the accuracy of the data entry.

Outcome Measure. The primary outcome measure was to determine the agreement of blood parameters including the white blood count, platelet count, and haemoglobin, between the conventional venous sample analyzed at the hospital laboratory and the capillary sample analyzed at the point of care.

Primary Data Analysis. The parameters were arbitrarily divided using the hospital laboratory normal ranges as a guide to form 3 subsets of low, normal, and high ranges for each parameter. Agreement between the 2 methods of blood parameter measurement was assessed by the statistical method of Bland and Altman [1] using $\mathrm{V}$ as the gold standard. The differences of capillary readings from their laboratory readings, that is, $\mathrm{C}$ versus $\mathrm{V}$ were compared by Wilcoxon-Signed-Rank test.

\section{Results}

A total of 314 consecutive patients were recruited into the study. Distribution of blood parameters from C and V sample readings within low, normal, and high ranges of their laboratory readings is presented in Table 2.

Similarly, the difference between blood parameters between $\mathrm{C}$ and $\mathrm{V}$ samples for their corresponding laboratory values for low, normal, and high ranges of their laboratory readings was presented in Table 3.

A statistically significant deviation from $\mathrm{V}$ compared to $\mathrm{C}$ samples was found for platelet $(P<0.001)$ and haemoglobin $(P<0.001)$. The magnitude of this difference was $7.3 \times$ $10^{9} / \mathrm{L}$ and $0.5 \mathrm{~g} / \mathrm{dL}$ for the low ranges of platelet counts and haemoglobin, respectively. There was no significant deviation for white counts between $\mathrm{V}$ and $\mathrm{C}$ samples. 
TABLE 2: Distribution of blood parameters from capillary samples (C) and venous samples (V) within low, normal, and high ranges of their laboratory readings.

\begin{tabular}{|c|c|c|c|c|c|c|c|}
\hline Blood parameter & Statistics & \multicolumn{6}{|c|}{ Laboratory range for blood parameter } \\
\hline \multirow{6}{*}{ White blood count $\left(\times 10^{9} / \mathrm{L}\right)$} & & \multirow{2}{*}{\multicolumn{2}{|c|}{$\begin{array}{c}\text { Low }(<4) \\
n=6\end{array}$}} & \multirow{2}{*}{\multicolumn{2}{|c|}{$\begin{array}{l}\text { Normal (4-10) } \\
\quad n=230\end{array}$}} & \multirow{2}{*}{\multicolumn{2}{|c|}{$\begin{array}{c}\text { High }(>10) \\
n=78\end{array}$}} \\
\hline & & & & & & & \\
\hline & & $\mathrm{C}$ & $\mathrm{V}$ & $\mathrm{C}$ & $\mathrm{V}$ & $\mathrm{C}$ & $\mathrm{V}$ \\
\hline & Mean & 2.65 & 2.85 & 7.36 & 7.44 & 13.25 & 13.29 \\
\hline & $\mathrm{SD}$ & 1.17 & 1.30 & 1.75 & 1.65 & 6.28 & 6.36 \\
\hline & Range & $0.50,3.90$ & $0.50,3.90$ & $3.60,11.70$ & $4.00,10.00$ & $8.80,62.10$ & $10.10,64.50$ \\
\hline & & \multicolumn{2}{|c|}{ Low $(<140)$} & \multicolumn{2}{|c|}{ Normal (140-440) } & \multicolumn{2}{|c|}{ High $(>440)$} \\
\hline \multirow[t]{6}{*}{ Platelet $\left(\times 10^{9} / \mathrm{L}\right)$} & & \multicolumn{2}{|c|}{$n=15$} & \multicolumn{2}{|c|}{$n=286$} & \multicolumn{2}{|c|}{$n=13$} \\
\hline & & $\mathrm{C}$ & $\mathrm{V}$ & $\mathrm{C}$ & $\mathrm{V}$ & $\mathrm{C}$ & $\mathrm{V}$ \\
\hline & Mean & 119 & 112 & 264 & 266 & 459 & 504 \\
\hline & SD & 24 & 26 & 63 & 62 & 67 & 60 \\
\hline & Range & 72,147 & 60,138 & 129,452 & 141,433 & 396,604 & 446,630 \\
\hline & & \multicolumn{2}{|c|}{ Low $(<13)$} & \multicolumn{2}{|c|}{ Normal (13-17) } & \multicolumn{2}{|c|}{ High $(>17)$} \\
\hline \multirow[t]{5}{*}{ Haemoglobin $(\mathrm{g} / \mathrm{dL})$} & & \multicolumn{2}{|c|}{$n=127$} & \multicolumn{2}{|c|}{$n=184$} & \multicolumn{2}{|c|}{$n=3$} \\
\hline & & $\mathrm{C}$ & $\mathrm{V}$ & $\mathrm{C}$ & $\mathrm{V}$ & $\mathrm{C}$ & $\mathrm{V}$ \\
\hline & Mean & 10.1 & 10.7 & 14.0 & 14.5 & 18.5 & 18.4 \\
\hline & $\mathrm{SD}$ & 1.9 & 1.9 & 1.2 & 1.0 & 1.2 & 0.8 \\
\hline & Range & $5.0,13.2$ & $5.0,12.9$ & $11.7,17.0$ & $13.0,16.9$ & $17.1,19.4$ & $17.7,19.3$ \\
\hline
\end{tabular}

TABLE 3: Difference $(d)$ in blood parameters of capillary samples from their corresponding laboratory values (C-V) for low, normal, and high ranges of their laboratory readings.

\begin{tabular}{|c|c|c|c|c|}
\hline \multirow{3}{*}{$\begin{array}{l}\text { Blood parameter } \\
\text { White blood count }\left(\times 10^{9} / \mathrm{L}\right)\end{array}$} & \multirow[t]{3}{*}{ Statistics for $d$} & \multicolumn{3}{|c|}{ Laboratory range for blood parameter } \\
\hline & & Low $(<4)$ & Normal (4-10) & $\operatorname{High}(>10)$ \\
\hline & & $n=6$ & $n=230$ & $n=78$ \\
\hline & Mean & -0.20 & -0.08 & -0.03 \\
\hline & $\mathrm{SD}$ & 0.35 & 0.68 & 1.20 \\
\hline & Range & $-0.60,0.20$ & $-1.50,2.72$ & $-2.40,3.60$ \\
\hline & Limits of agreement ${ }^{\S}$ & $-0.89,0.49$ & $-1.41,1.25$ & $-2.38,2.32$ \\
\hline \multirow{6}{*}{ Platelet $\left(\times 10^{9} / \mathrm{L}\right)$} & & Low $(<140)$ & Normal (140-440) & High $(>440)$ \\
\hline & & $n=15$ & $n=286$ & $n=13$ \\
\hline & Mean & 7.3 & -2.2 & -45.8 \\
\hline & $\mathrm{SD}$ & 9.4 & 31.3 & 31.4 \\
\hline & Range & $-11,30$ & $-84,76$ & $-93,20$ \\
\hline & Limits of agreement ${ }^{\S}$ & $-11.1,25.7$ & $-63.6,59.2$ & $-107.3,15.7$ \\
\hline \multirow{6}{*}{ Haemoglobin $(g / d L)$} & & Low $(<13)$ & Normal (13-17) & $\operatorname{High}(>17)$ \\
\hline & & $n=127$ & $n=184$ & $n=3$ \\
\hline & Mean & -0.5 & -0.5 & 0.1 \\
\hline & SD & 0.4 & 0.5 & 0.7 \\
\hline & Range & $-1.9,0.9$ & $-1.9,0.9$ & $-0.6,0.7$ \\
\hline & Limits of agreement ${ }^{\S}$ & $-1.3,0.3$ & $-1.5,0.5$ & $-1.3,1.5$ \\
\hline
\end{tabular}

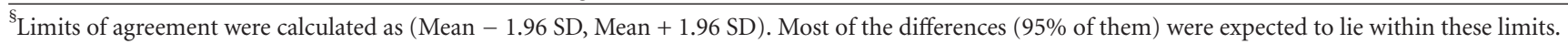

\section{Correlation and Regression}

For each blood parameter the result from the analyzer was compared with the hospital haematology value. Correlation coefficients were calculated to report the relationship between the $\mathrm{V}$ and $\mathrm{C}$ sample results. Additionally, linear regression of the $\mathrm{FBC}$ analyzer $\mathrm{C}$ sample result (dependent variable) on the $\mathrm{V}$ sample result (independent variable) was done for each blood parameter.

Figures 1, 2, and 3 show the correlation of the FBC analyzer $\mathrm{C}$ result with the $\mathrm{V}$ value for each blood parameter. The coefficient of correlation, $r$, was high, above 0.90 for 
TABLE 4: Correlation of blood parameters from FBC analyzer (C) samples with corresponding LAB samples.

\begin{tabular}{lccc}
\hline & WBC & Plt & Hb \\
\hline$r$ & 0.982 & 0.927 & 0.980 \\
Slope coefficient & 0.985 & 0.878 & 0.998 \\
Intercept & 0.058 & 29.223 & -0.489 \\
\hline
\end{tabular}

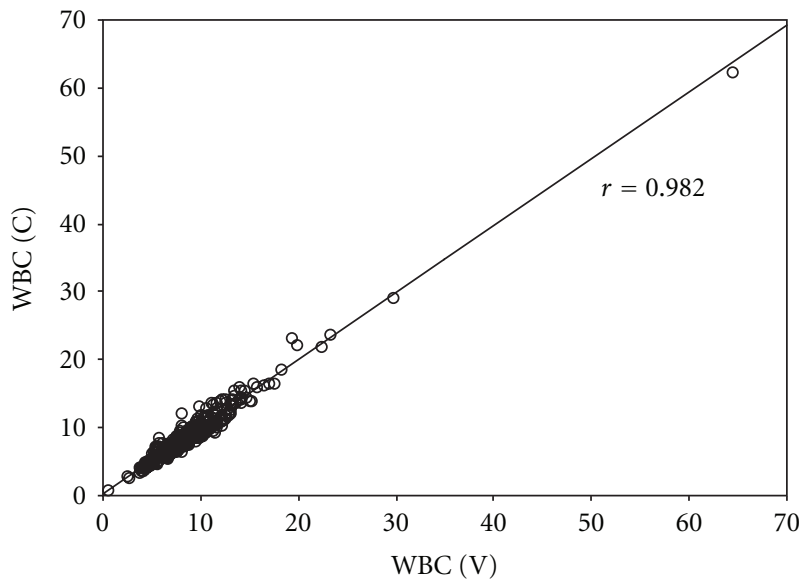

Figure 1: Plot of white blood cell (WBC) counts by capillary (C) versus venous $(\mathrm{V})$ blood sample.

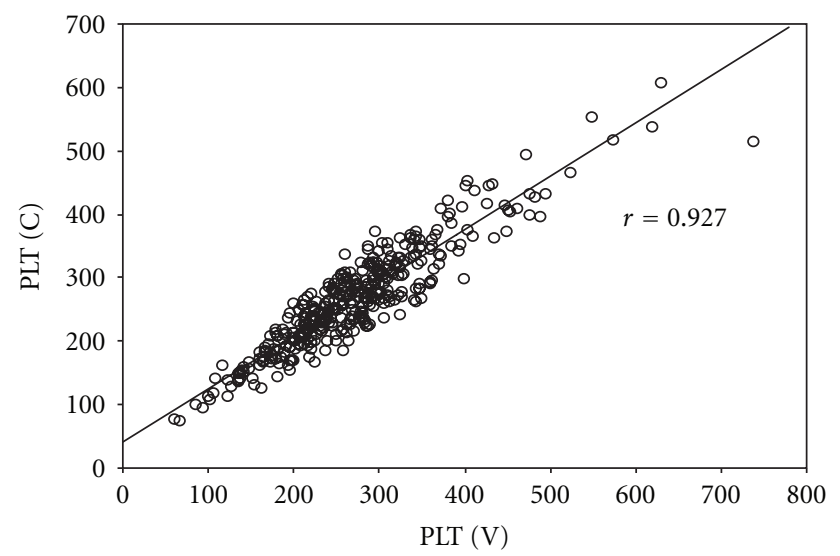

Figure 2: Plot of platelet counts by capillary (C) versus venous (V) blood sample.

all 3 parameters. Table 4 shows the regression coefficient and intercept resulting from the regression for each blood parameter. For WBC and $\mathrm{Hb}$, the slope coefficients were near 1 and the intercept near 0 , an indication that the analyzer $C$ values were very similar to the $\mathrm{V}$ values.

\section{Limitations}

There are several limitations to the study including the following.

(1) The study did not take into account demographic information of the subjects, the reason for the index ED visit (e.g., were these patients acutely ill

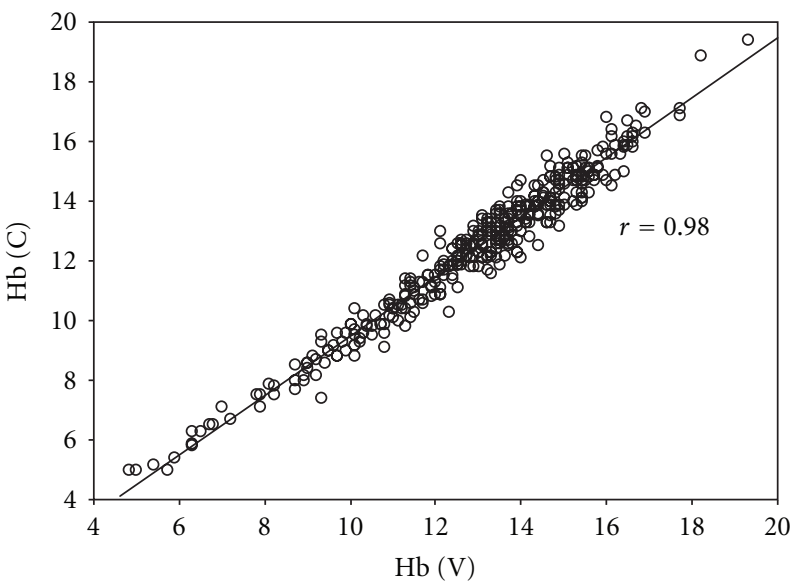

Figure 3: Plot of haemoglobin ( $\mathrm{Hb}$ ) measurement by capillary $(\mathrm{C})$ versus venous $(\mathrm{V})$ blood sample.

and requiring admission), comorbidities (especially blood dyscrasias or malignancy, immunosuppression such as AIDS, etc.), and diagnoses.

(2) The number of patients with blood parameters in the abnormal ranges was small and hence interpretation of the results in this category of patients' should be done with caution.

(3) The study also excluded patients who were undergoing resuscitation, patients who had unstable vital signs, and who may have peripheral vasoconstriction and decreased capillary blood flow in the extremities.

With the above limitations, the external validity and generalizability of the study are limited. Further studies need to be done taking into consideration these specific categories of patients to determine the clinical applicability of capillary blood count analysis under these conditions.

\section{Discussion}

The use of capillary blood samples for the analysis of FBC has been evaluated in the past for the neonatal and paediatric populations and has been found to be helpful in clinical practice. However, there have been conflicting results from several studies that show significant differences between the capillary and venous FBC parameters that are measured [2$6]$.

In one study on healthy adult volunteers [3], there was no statistically significant difference between capillary and venous samples for haemoglobin and platelet counts but was noted to have statistically significant elevated white cell 
counts in capillary samples. Another similar study [4] on healthy volunteers had shown lower platelet counts, elevated white counts and haemoglobin values in capillary blood compared to venous samples. Other studies $[5,6]$ on platelet counts in healthy volunteers and patients with known low platelet counts noted the difference between the capillary and venous platelet counts to be higher in the healthy volunteers, while there was poor correlation between the venous and capillary samples in patients with low platelet counts. Although it is not clear why the contradiction in the results especially with regards to platelet counts, one possible explanation could be the delay in analysis of the capillary samples sent to the laboratory in the former study [4]. This may have resulted in platelet aggregation and hence lower platelet counts in the capillary sample as opposed to the higher counts in our study, where the samples were analysed at the POC almost immediately after sample collection.

However, considering clinically relevant situations in the ED, the absolute differences between the capillary and venous samples in the platelet count, white cell count, and haemoglobin values for the low and high ranges in our study are acceptable in the clinical context and are unlikely to result in any adverse outcomes. In addition, safeguards could be built in the decision making process to seek laboratory confirmation by means of a second sample of venous blood analysed at the hospital laboratory for those patients having abnormal capillary blood parameters. This would greatly cut down on the number of venous samples needed for analysis, as only a smaller cohort of the screened population will be expected to have abnormal values. For patients with counts in the normal ranges, they should be referred for repeat blood counts as clinically indicated.

There are several benefits from employing the use of capillary FBC analysis in the ED setting. Its simplicity allows nurses and other paramedical staff to be trained to collect samples, which are fed into automated FBC analyzers at the POC. This reduces the dependence on physicians or phlebotomists for venepuncture, cuts down the logistics for transporting specimens to the laboratory and for laboratory technicians to do the analysis. Being minimally invasive with small sample requirements makes it convenient for the patient and is especially useful in the setting of patients with difficult venous access.

Hence, capillary sampling and POC blood count analysis when deployed as screening for the large volume of ED patients could cut down the time delay for decision making, potentially allowing faster patient turnaround times. Deploying this capability at the triage point in a busy ED can enhance and empower the triage officer in making clinically relevant decisions. This further reduces the congregation and crowding of patients in secluded "fever areas" of ED with potential for cross infections thus reducing the spread of infectious diseases amongst patients and accompanying guests. This is especially relevant in these times with recent memories of the severe acute respiratory distress syndrome (SARS) epidemic and bird flu outbreaks. This is expected to possibly reduce the overall costs, expedite care by reducing waiting time for decision making and shortening turnaround times reducing overcrowding, and improve convenience and comfort for the patients without compromising safety.

As with any POC test, the use of such tests should be guided by strict quality control measures and proper maintenance of equipment in order to maintain a high level of reliability and accuracy of the tests.

In Retrospect. The study could have been conducted with a larger sample size and focussed on patients with sepsisor anaemia-related conditions so that the accuracy of the capillary sample blood parameters could be extrapolated to this group of patients. It would also have been able to capture more patients who are likely to have abnormal blood parameters.

In summary, it was noted that analysis of capillary blood samples for FBC parameters is as reliable compared to conventional venous blood testing in laboratories with the following benefits.

(1) It is a potentially useful tool to assist the physician in making a rapid assessment and diagnosis at POC facilitating patient management.

(2) It is a convenient, minimally invasive testing method with fast turnaround times reducing patient waiting time and enhancing convenience.

\section{Acknowledgments}

All Eights Singapore Private Limited distributor of Medonic CA 620 , manufactured by Boule Medical, funded the use of the automated analyzer and expendables (instrument reagents, capillary tubes, medlance needles) needed for carrying out the study. There was no monetary aid (direct or indirect) provided to the authors or the institution in relation to this study. The authors have no financial interest in the product studied or the company that produces it.

\section{References}

[1] J. M. Bland and D. G. Altman, "Statistical methods for assessing agreement between two methods of clinical measurement," The Lancet, vol. 1, no. 8476, pp. 307-310, 1986.

[2] S. M. Kayiran, N. Özbek, M. Turan, and B. Gürakan, "Significant differences between capillary and venous complete blood counts in the neonatal period," Clinical and Laboratory Haematology, vol. 25, no. 1, pp. 9-16, 2003.

[3] Z. W. Yang, S. H. Yang, L. Chen, J. Qu, J. Zhu, and Z. Tang, "Comparison of blood counts in venous, fingertip and arterial blood and their measurement variation," Clinical and Laboratory Haematology, vol. 23, no. 3, pp. 155-159, 2001.

[4] L. N. W. Daae, S. Halvorsen, P. M. Mathisen, and K. Mironska, "A comparison between haematological parameters in 'capillary' and venous blood from healthy adults," Scandinavian Journal of Clinical and Laboratory Investigation, vol. 48, no. 7, pp. 723-726, 1988. 
[5] J. H. Feusner, J. A. Behrens, J. C. Detter, and T. C. Cullen, "Platelet counts in capillary blood," American Journal of Clinical Pathology, vol. 72, no. 3, pp. 410-414, 1979.

[6] D. Y. Tai, K. W. Chan, Y. C. Chee, and K. H. Mak, "Comparison of platelet counts in simultaneous venous and capillary blood samples using an automated platelet analyser," Singapore Medical Journal, vol. 36, no. 3, pp. 263-266, 1995. 


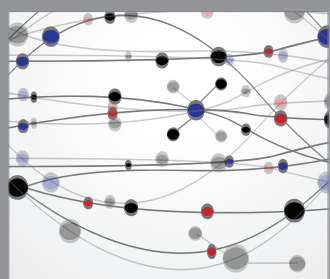

The Scientific World Journal
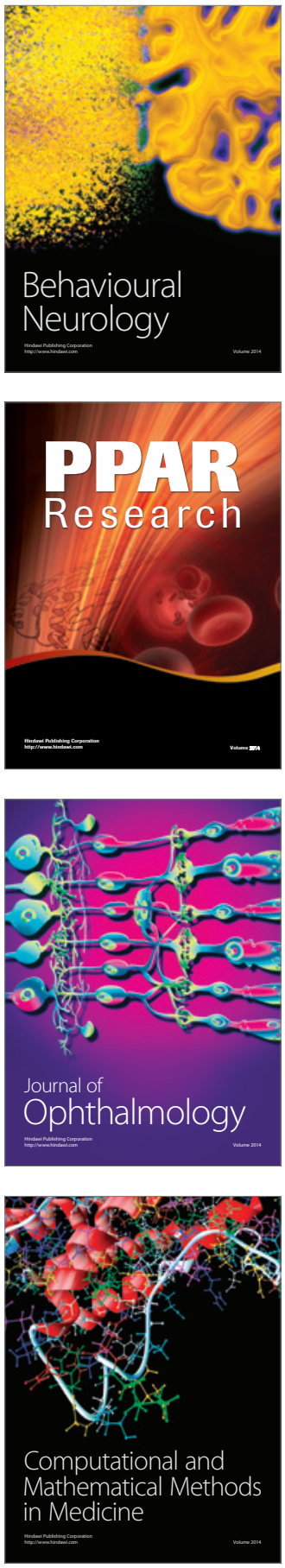

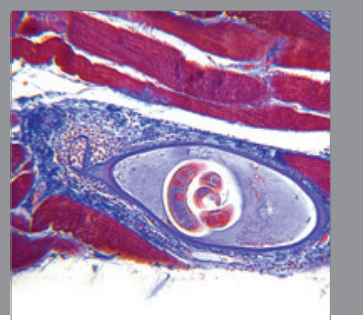

Gastroenterology

Research and Practice
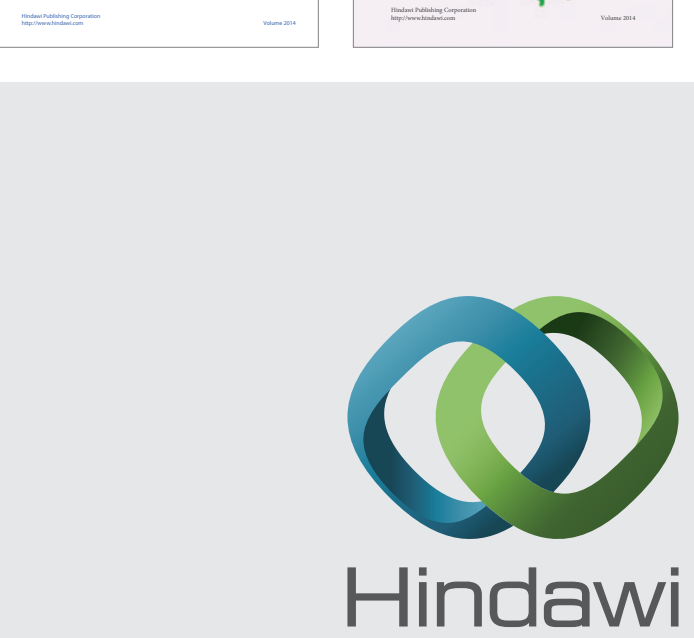

Submit your manuscripts at

http://www.hindawi.com
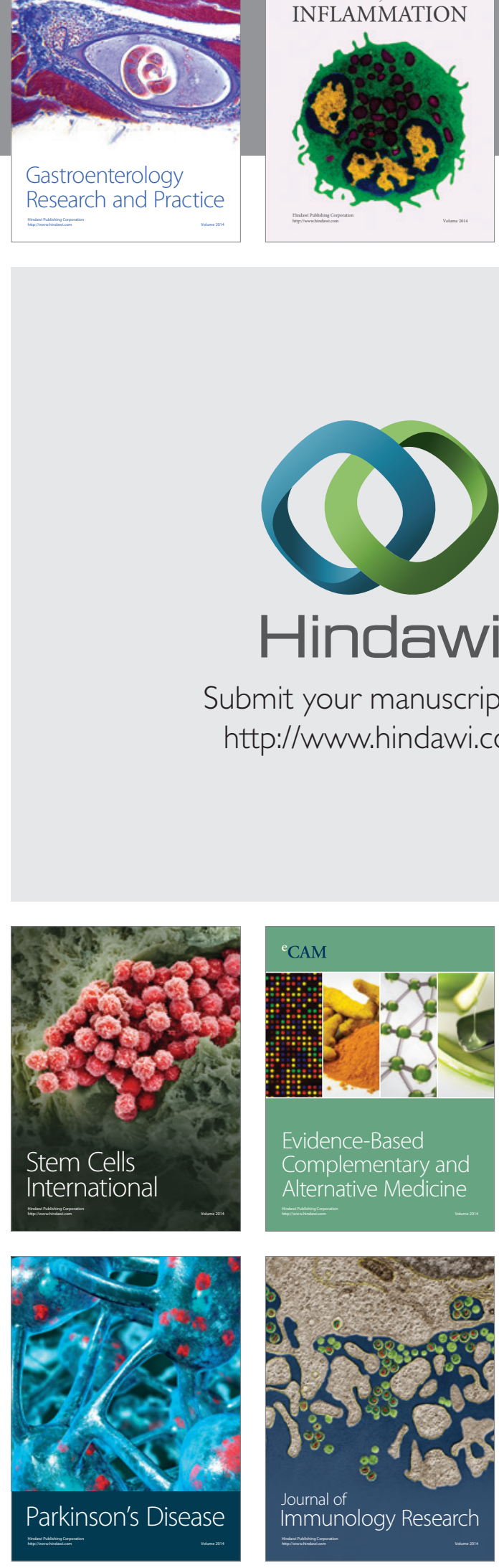

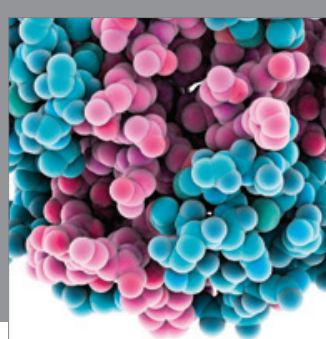

Diabetes Research
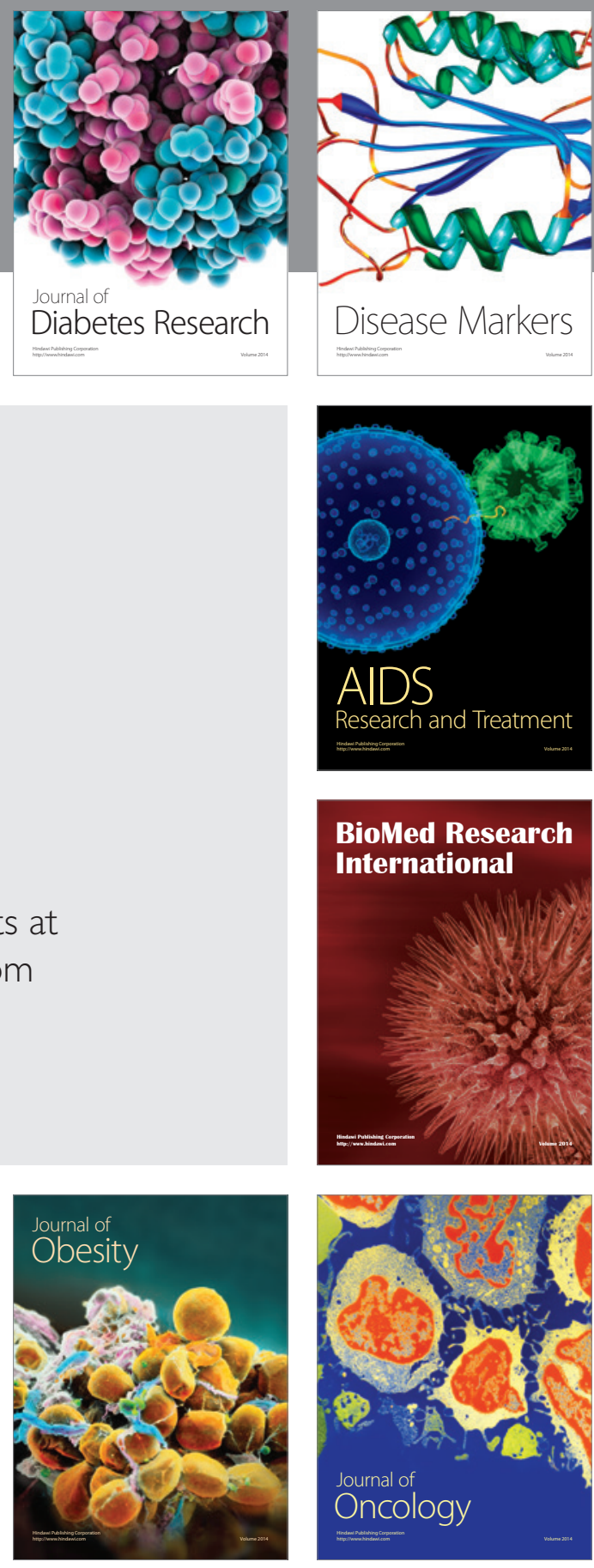

Disease Markers

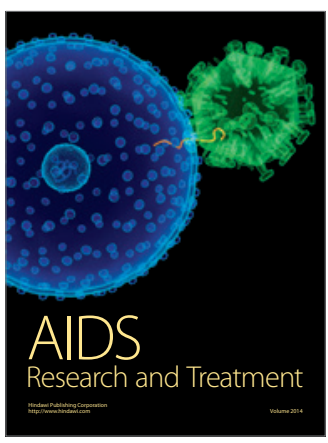

BioMed Research

International
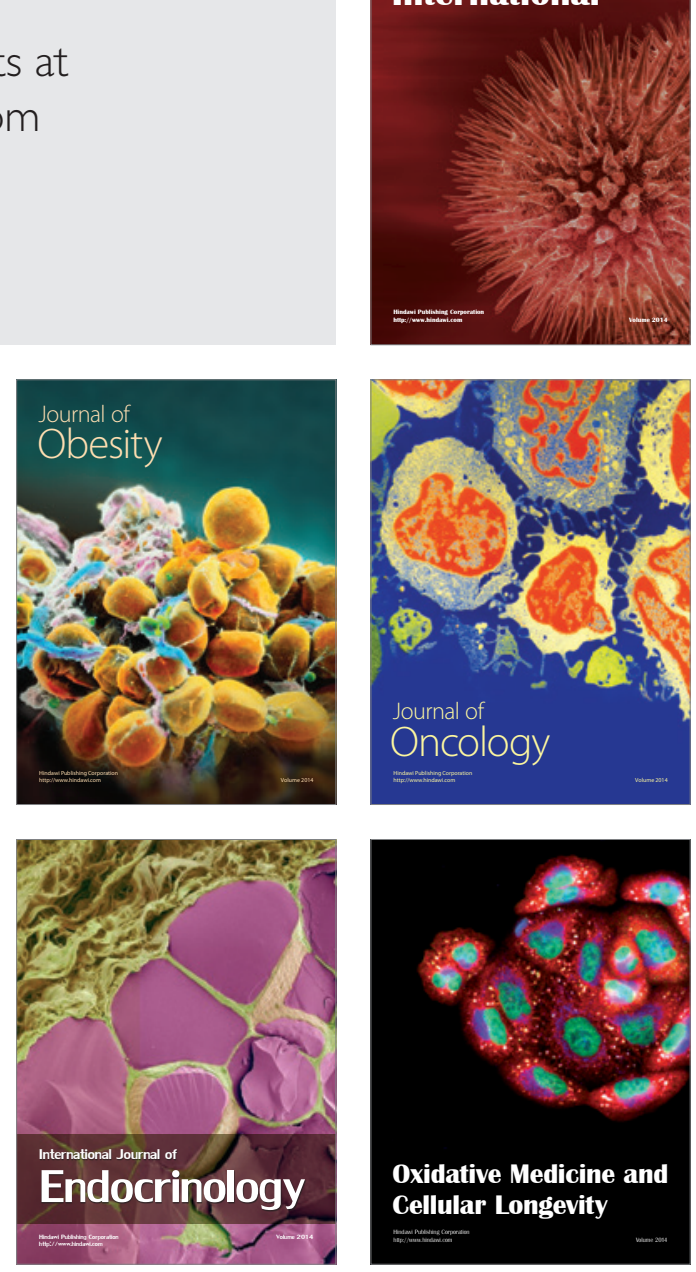